\title{
Uma proposta de análise intersemiótica do gênero GIF poem a partir de "Asas" e "Volve", de Arnaldo Antunes
}

\author{
Livia Ribeiro Bertges* \\ Vinícius Carvalho Pereira**
}

\section{Resumo}

O suporte, como integrante e mesmo determinante de novas experiências estéticas, fomenta distintas formas de interação e leituras de textualidades poéticas. No contexto dos novos suportes advindos da revolução digital, o formato GIF, popular em ambientes virtuais, tem sido usado em processos de reelaboração de poemas originalmente publicados em meio impresso. Nesse contexto, o presente artigo analisa duas transposições das séries poéticas "Asas" (2015) e "Volve" (2012), de Arnaldo Antunes, para o gênero poema em GIF animado. Tais poemas estabelecem e potencializam fenômenos de movência, velocidade e repetição, dinâmicas inerentes a esse novo gênero de poesia digital. Para tanto, discutimos questões espaciotemporais caras à poesia visual, no que tange à transposição de "Asas" e "Volve" para o formato GIF, à luz das metáforas do caleidoscópio e da luneta, instrumentos ópticos que medeiam a relação entre aquele que vê e aquilo que é visto, desnaturalizando poeticamente a percepção.

Palavras-chave: Arnaldo Antunes. GIF poems. Movência. Repetição.

\section{Introdução}

O desenvolvimento tecnológico de novos suportes, como integrante e mesmo determinante de inauditas experiências

\footnotetext{
Doutoranda em Estudos de Linguagem pela Universidade Federal de Mato Grosso (UFMT), com estágio doutoral na Université Paris-Sorbonne. E-mail: livia. bertges@gmail.com

** Professor do Departamento de Letras e do Programa de Pós-Graduação em Estudos da Linguagem (UFMT), com estágio pós-doutoral na University of Nottingham. E-mail: viniciuscarpe@gmail.com
}

Data de submissão: 26/07/2017 - Data de aceite: ago. 2017 http://dx.doi.org/10.5335/rdes.v13i2.7250 
estéticas, fomenta distintas formas de interação e leituras de textualidades poéticas emergentes, seguindo um paradigma que McLuhan (1974) sacralizou no aforisma "o meio é a mensagem".

No contexto dos suportes advindos da revolução digital, uma série de novos gêneros pode ser identificada, para os quais ainda se estão elaborando teorias e modelos críticos, ou mesmo simples taxonomias gerais que norteiem a identificação desse campo literário. Para se ter uma ideia da diversidade de gêneros que integram a literatura digital, podem-se tomar os que a Electronic Literature Organization (ELO, 2015), a maior associação da área atualmente em todo o mundo, cita em sua página da $w e b$ que introduz o conceito de e-lit (electronic literature ou literatura eletrônica, em português): ficção e poesia hipertextuais, dentro e fora da $w e b$; poesia cinética apresentada em Flash e usando outras plataformas; instalações de arte computacional que convidam o público à sua leitura ou apresentam aspectos literários; personagens conversacionais, também chamados de chatterbots; ficção interativa; aplicativos literários; romances em forma de e-mails, mensagens de texto ou blogs; poemas e histórias gerados por computadores, tanto de modo interativo quanto com base em parâmetros definidos a priori; projetos de escrita colaborativa que permitem que os leitores contribuam com o texto de uma obra; performances literárias on-line que desenvolvem novas formas de escrita (ELO, 2015).

Ainda que extensa, a lista não cobre todas as possibilidades de realização estética na área de literatura digital, seja pela limitação que qualquer classificação de gênero impõe diante da plasticidade das manifestações artísticas, seja pela diversidade de recursos formais engendrados por cada nova tecnologia desenvolvida. Nesse sentido, parece-nos faltar, no inventário de gêneros acima, um que é praticado pelo artista brasileiro Arnaldo Antunes: o GIF poetry, ou poesia em formato GIF (Graphics Interchange Format).

Popular em ambientes virtuais para expressão de mensagens multimodais, unindo texto verbal e não verbal, esse recurso já foi usado por diferentes artistas, como Anatol Knotek e Augusto de Campos, seja em obras desenvolvidas especialmente para esse formato, seja para processos de reelaboração de poemas originalmente publicados em meio impresso. Em todo caso, importa esclarecer que a tensão entre imagem e palavra não é algo recente: já estava presente nos estudos do gênero lírico desde a Grécia Antiga e foi retomada de diferentes maneiras ao longo da história da literatura. O que é "novo", no caso da literatura digital, é o suporte não analógico em que o verbal e o não verbal podem se relacionar. Além disso, mais especificamente no gênero do GIF poetry, destacam-se as particularidades técnicas (e as limitações expressionais) desse tipo 
de arquivo de imagem, desenvolvido originalmente em 1987, mas usado ainda no século XXI. A relativa "antiguidade" dessa mídia, considerando a velocidade com que se desenvolveu a computação gráfica nos últimos 30 anos, impõe-lhe uma aura vintage diante do público de hoje, que vê no GIF formas menos realistas de representação imagística na internet.

Entre os artistas que produzem poesia visual no formato GIF, destaca-se o brasileiro Arnaldo Antunes, que atua como poeta, músico, compositor e performer, frequentemente sobrepondo esses papéis; assim, como poeta, seus textos frequentemente saem do livro, passam pelas notas musicais, pelo corpo e pela voz do recitador, ou pelas telas de cristal líquido. Trata-se, pois, de uma obra multimídia por definição, da qual se pode ter uma ideia panorâmica a partir de seu website ${ }^{1}$ (ANTUNES, [201-]). Nesse portal, entre várias outras produções, o autor apresenta, dentro da aba "Artes", alguns poemas visuais em formato $G I F$ animado (uma composição dinâmica de diferentes imagens, conforme se detalhará mais à frente), nos quais abundam elementos plásticos na exploração do verbal e do não verbal.

A fim de compreender melhor as especificidades expressionais de tal gênero na obra de Antunes, proceder-se-á neste artigo a uma análise dos GIFs animados "Asas" e "Volve", ${ }^{2}$ os quais foram produzidos a partir de poemas visuais impressos e homônimos, originalmente publicados nos livros Tudos (2015), publicado pela primeira vez em 1990, e 2 ou + corpos no espaço (2012), publicado pela primeira vez em 1997, respectivamente.

Interessa-nos enfocar como o uso desse formato de mídia implica um movimento transtextual no ciberespaço, no qual Arnaldo Antunes, em face ao seu retorno à tradição concreta da poesia brasileira, já assinalado por Joeci Helena de Moraes (2007), Simone Silveira Alcântara (2010) e Ana Paula Ferreira (2010), transpassa as modulações do sistema livresco para apropriar-se das novas tecnologias e suscitar inusitadas semioses entre a letra e a imagem, o analógico e o digital. Assim, norteando a reflexão ora iniciada, está a seguinte questão: em que medida o GIF poetry de Arnaldo Antunes pode ressignificar poemas impressos a partir da adaptação intersemiótica inerente à transposição desse gênero, considerando as especificidades técnicas e fenomenológicas de arquivos em GIF animado?

\section{Graphics Interchange Format: possibilidades e limitações}

Em linhas gerais, pode-se dizer que GIF é um protocolo relativamente simples de arquivos de imagem no universo digital, os quais admitem até oito bits por pixel para cada imagem, com uma paleta de, no máximo, 256 cores (NADAL, 
2014). Sua simplicidade torna o formato bastante popular nos dias de hoje, mas implica, ao mesmo tempo, limites de coloração, falta de áudio e baixa resolução da imagem (AMARAL, 2016). Devido a isso, para mensagens em que a imagem se queira fidedigna representação do real, os GIFs são atualmente pouco empregados, mas seu uso ainda é comum em aplicações em que as limitações técnicas da representação imagética ganham valores expressivos, como na estética kitsch. Um exemplo de imagem em $G I F$, retirado do site de Arnaldo Antunes, pode ser visto na Figura 1.

Figura 1 - Imagem em formato GIF

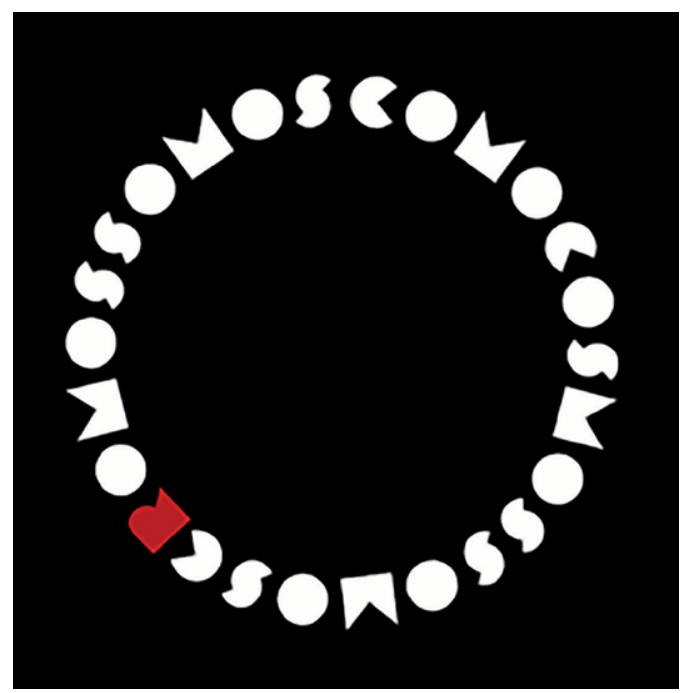

Fonte: Antunes ([201-?]).

Além disso, ainda do ponto de vista técnico, pode-se, com tal tecnologia, produzir um GIF animado, isto é, um arquivo composto por uma técnica serial de montagem de imagens de baixa resolução, as quais se sucedem automaticamente numa tela de computador ou de dispositivo móvel. Em termos de efeitos estéticos, a animação imprime ao GIF plasticidade, velocidade e repetição, muitas vezes rodando em loop.

Como as imagens que se sucedem representam frames geralmente bastante distintos, a visualidade do GIF animado não tem a fluidez de um vídeo; em vez disso, há transições abruptas entre os frames, o que enfatiza o efeito kitsch do formato aparentemente simples de arquivo de imagem. Para fins de clareza (e considerando as limitações de reproduzir num arquivo de texto os efeitos visuais de um GIF animado), decompomos em frames sucessivos, na Figura $2,^{32}$ parte de um poema em GIF animado constante no site de Arnaldo Antunes.

Figura 2 - Frames sucessivos de poema em GIF animado
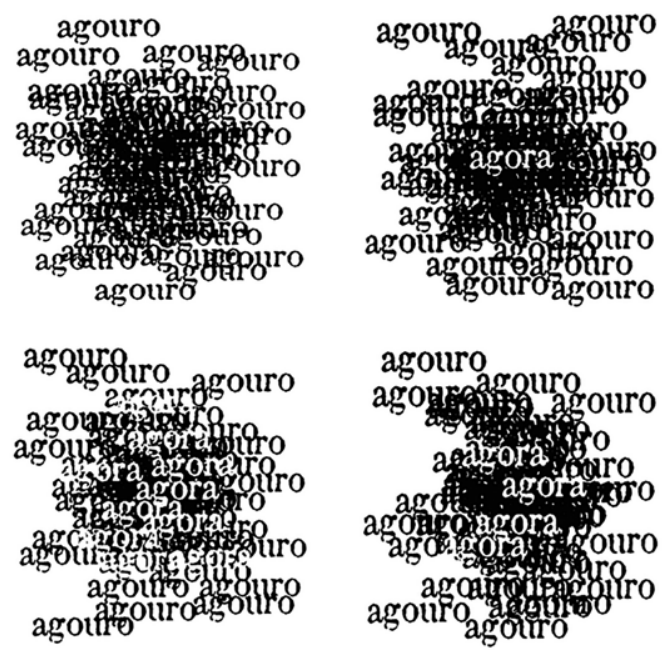

Fonte: Antunes ([201-?]). 
Nota-se, a partir desses frames, que há mudanças significativas entre as imagens, o que, a depender da velocidade com que elas se sucedam na tela, pode gerar diferentes efeitos sobre o leitor, desde uma estética da fragmentação até a sensação de vertigem. De todo modo, destaque-se aqui que o gênero GIF poem pode abarcar produções poéticas bastante variadas dentro do mesmo formato digital, de imagens estáticas a imagens que se sucedem dinamicamente, gerando a sensação ótica de movimento.

Considerando ainda o papel crescente que o universo digital tem desempenhado nas relações humanas e mesmo nas práticas estéticas, pode-se considerar a poesia em GIF um fenômeno em plena floração, na medida em que a facilidade de captura de imagens nesse formato gera novas e acessíveis possibilidades de interação entre os meios digitais e um encontro propício entre artes plásticas, design e poesia. Com fácil inserção nas plataformas da internet, tais produções podem ser fixadas em redes sociais, em blogs ou em sites, recebendo diferentes nomenclaturas, como "fotopoemas" ou "poemaimagens". ${ }^{4}$ No presente artigo, porém, adota-se a nomenclatura GIF poem, a fim de ressaltar a potencialidade do formato do arquivo, juntamente com uma noção de poema como estrutura verbo-visual, cara à obra poética de Arnaldo Antunes.

Observando-se mais atentamente $o$ site do poeta, nota-se uma preponderância, entre os arquivos em GIF, de textos no formato GIF animado, o que aponta para uma estética da dinamicidade, mais do que da estaticidade, no uso que Antunes faz dessa tecnologia. Considerando ainda o caráter performático da obra de Arnaldo Antunes como um todo, parece-nos coerente com sua poética essa opção pelo GIF animado, lançando o leitor em experiências verbo-visuais em que os traços - de letras, palavras ou desenhos - repudiam qualquer imobilidade visual ou interpretativa.

Parece-nos aí haver um paralelo com o que Barthes aponta como característico tanto da produção poética contemporânea quanto do olhar contemporâneo para a literatura: um "efeito de uma droga", de deslocamento do foco, de desfoque, como em um descontrole perante a matéria textual em regimes semióticos diferentes. Nas palavras do autor,

[...] on relit tout de suit le texte, c'est pour obtenir, comme sous l'effet d'une drogue (celle du recommencement, de la différence), non le 'vrai' texte, mais le texte pluriel: même et nouveau (1970, p. 23). ${ }^{5}$

Este texto plural que é, a um só tempo, ele mesmo e outro é todo poema que se abre à polissemia e rompe com a representação, como lia Barthes a literatura contemporânea. Nesse sentido, os poemas em GIF animado realizam tal promessa em termos materiais, exibindo diante do leitor uma sequência de imagens que faz do texto ele mesmo, mas sempre se abrindo para um devir-outro na série. Trata-se, em última medida, de uma propriedade que Hayles (2006) atribuíra a toda a literatura digital, em 
que uma obra não é jamais idêntica a si mesma, dadas as impermanências que caracterizam o ciberespaço.

Também como performance - que sempre muda e é única, mas varia em torno de um núcleo comum (do script, do material usado ou do espaço ocupado)-, o GIF animado é movimento, mas é repetição. A trajetória do movimento é, nesse formato, circular e cíclica, o que põe em questão outras dimensões do poético no jogo entre o singular e o plural.

Diante do GIF não só como formato - mas também como ato - de repetição, questionamo-nos, por analogia, se todo poema não é também um exercício de repetição, seja no nível fônico, com rimas, ritmos e aliterações; seja no nível sintático, com paralelismos e quiasmas; seja no nível semântico, com isotopias (GREIMAS, 1973); seja, enfim, no nível da enunciação, visto que cada declamação faz daquele poema um acontecimento único e dinâmico, ainda que motivado por um núcleo comum e estático: a imanência do verso impresso.

Nessa dialética entre unicidade e serialidade, diferença e repetição, que todo poema enseja, mas o GIF animado radicaliza, sequenciando automaticamente imagens, vale retomar Deleuze para quem

Todo o fenômeno remete para uma desigualdade que o condiciona. Toda a diversidade e toda a mudança remetem para uma diferença que é a sua razão suficiente. Tudo o que se passa e aparece é correlativo de ordens de diferenças: diferença de nível, de temperatura, de pressão, de tensão, de potencial, diferença de intensidade (1988, p. 209).
Sob tal perspectiva, a diferença é a condição ontológica de as coisas serem elas mesmas. É pela diferença que se isolam as semelhanças, as estruturas e as condições de interpretação do fenômeno. Um poema em GIF animado, construído literalmente a partir de diferenças e repetições de imagens em uma sequência fechada - mas cíclica e ininterrupta -, materializa no universo digital a potencialidade que toda poesia encerra de se constituir a partir de um núcleo reiterado a cada variação de si.

No caso dos poemas em GIF animado de Arnaldo Antunes, esse jogo de diferença e repetição é ainda mais significativo, uma vez que tais produções são transposições, para o universo digital, de poemas visuais originalmente publicados em livros impressos. Nesse caso, a serialidade do que se repete atravessa não só uma sequência temporal, mas também material, na medida em que atravessa diferentes suportes. Dobrado sobre si mesmo, cada um desses poemas é feito de uma repetição de segundo grau, como um gerador de reiterações das imagens em si, originalmente criadas em papel. Operam-se, pois, relações transtextuais (GENETTE, 2006) que cruzam textos distintos - na intertextualidade entre cada poema impresso e sua transposição para o formato digital - e variações do mesmo texto - na intratextualidade das relações diferenciais que as imagens sequenciadas estabelecem no GIF animado. 
Nesse caráter plural de seriação e (re)montagem, os poemas em GIF animado colocam desafios à leitura, que envolve não mais só os tempos do leitor, do enunciado e da enunciação - há muito conhecidos da Teoria Literária -, mas também o tempo do sistema (KOSKIMAA, 2010), isto é, a periodicidade em que as imagens do GIF se alteram a cada minuto (ou mesmo segundo, a depender do arquivo). Por sua vez, no suporte impresso, as diferentes imagens que compunham as séries poéticas "Asas" e "Volve" eram impressas em páginas separadas, o que dava ao leitor a chance de controlar o tempo de "mudança" da imagem diante dos seus olhos, cadenciando, conforme seu tempo próprio de leitura e interpretação, o deslocamento da série. Talvez, aliás, seja esta uma das principais distinções fenomenológicas com que Antunes defronta o leitor ao produzir, com as mesmas imagens, versões impressas e em GIF animado de "Asas" e "Volve": as diferentes maneiras como as temporalidades do leitor, do enunciado, da enunciação e do sistema podem confluir em experiências estéticas diante da obra. Nesse sentido, está o projeto poético de Antunes em consonância com o que Santos afirmara para toda a estética digital:

O ciberespaço parece proporcionar uma espécie de justaposição de várias temporalidades (resultando, em parte, na efemeridade mencionada). Ele nos permite, por exemplo, num só golpe, perscrutar formas e funções de telescópios direcionados para o fundo do universo (2003, p. 38).
Diante das impermanências e acelerações que compõem a poesia em GIF animado, assim como diversas outras obras da literatura digital, há que se definir, pois, novas estratégias de leitura e metodologia de análise, uma vez que a crítica acadêmica - de que este artigo é um exercício - está mais habituada a textualidades cuja mobilidade se dá tão somente no plano semântico e interpretativo, e não na configuração material.

A esse respeito, Santos coloca como crucial para compreender as leituras no meio digital o entendimento não só das textualidades explícitas na interface, mas também das estratégias e dos recursos que a obra mobiliza por meio de um código que é, em si mesmo, também texto, pois se trata da escrita de uma linguagem de programação. No caso do presente artigo, que analisa poemas que se alteram em loop diante dos olhos do leitor, optamos pelo recurso à captura de telas, a fim de permitir uma mais detalhada apreciação dos objetos poéticos e de suas diferentes configurações visuais. No entanto, quando necessário à análise, faremos remissão não apenas aos GIFs animados, mas também às séries impressas "Asas" e "Volve", entendendo as versões digital e analógica não como obras radicalmente distintas, mas sim como diferentes versões oriundas da "sedimentação de processos textuais variados”, conforme Santos aborda: 
Talvez essa diferença entre conjunção e justaposição ajude a discernir melhor a maneira como se esboça, então, uma linha que leva da literatura da tradição impressa a uma pretensa literatura eletrônica. Assim, não se fala nem de continuidade, nem de ruptura radical, mas de sedimentações de processos textuais variados, podendo colocar no mesmo saco o projeto do Livre, de Mallarmé, e propostas vanguardistas propagandeando a própria extinção do livro. E por isso que falar da literariedade dos hipertextos eletrônicos significa dar conta desse intrincado jogo que não pode mais ser resumido simplistamente a uma escolha entre diacronia e sincronia (SANTOS, 2003, p. 64).

\section{Do caleidoscópio à luneta: jogos ópticos nos GIFs animado "Asas" e "Volve"}

A série poética "Asas", originalmente publicada por Antunes como um conjunto de cinco imagens impressas no livro Tudos (2015), foi transposta pelo próprio autor para o formato de GIF animado com apenas três imagens, as quais são reproduzidas a seguir, a partir de capturas de tela do poema digital. No entanto, para melhor acompanhar a análise ora empreendida, sugere-se ao leitor do presente artigo que acesse o site do poeta, a fim de experienciar o GIF poem "Asas" em seus diferentes recursos semióticos, sobretudo os efeitos de repetição e velocidade.
Figura 3 - Frames sucessivos do poema "Asas" em GIF animado


Fonte: Antunes ([201-?]).

$\mathrm{Na}$ primeira ${ }^{6}$ imagem da série do poema em $G I F$, o leitor logo nota uma sequência vertical de letras "a" no canto esquerdo, acompanhada por um conjunto de sinuosas linhas ao centro da imagem, que acabam formando contornos de "s". O traçado das letras não remete a nenhuma tipografia ou mesmo à escrita à mão: mais parece tratar-se de uma estilização das letras, como a que se pratica em assinaturas. A baixa legibilidade das garatujas lança o leitor, desde o primeiro frame do GIF, a um estranhamento: ainda que se trate de letras conhecidas, sua disposição e seu delineamento reduzem a possibilidade de interpretar imediatamente a imagem, causando o efeito de desaceleração e desautomatização de leitura esperado de qualquer poema.

O GIF animado tem uma velocidade própria de substituição das imagens, que se choca com a dificuldade inicial de leitura das letras "a" e "s" tão estilizadas. 
Assim, talvez o leitor sequer as reconheça no primeiro ciclo de rotação do $G I F$, devendo acompanhar sua reiteração por algum tempo até conseguir entrever os grafemas gatafunhados.

No entanto, caso opte por congelar a primeira imagem (como feito na análise ora relatada), pode um olhar mais demorado e atento enxergar, no desenho caligráfico, também a imagem de uma asa, formada por superposição de cinco ocorrências da palavra "asas", que dá título à série e remete à ideia de movimento ritmado e repetitivo, caro ao gênero GIF poem. A repetição, nesse caso, é não só do bater das asas, nem da transformação das imagens, mas também das palavras que, "empilhadas" e ligeiramente inclinadas, formam uma construção verbal de cinco camadas - algo análogo a uma estrofe de cinco versos. A coesão visual entre essas palavras sobrepostas, unindo-as em um todo plástico, dá-se pelo flexuoso movimento da letra "s", que acaba por conectar diversos pontos da imagem e dar-lhe uma conotação de repetição e movimento que o morfema de plural - ele mesmo, um "s" - indica na palavra "asas".

Já na segunda imagem da série, observam-se apenas quatro palavras "asas", as quais estão inclinadas como se tivessem sofrido uma rotação no sentido anti-horário. Essa sensação de movimento, produzida por uma nova disposição dos elementos gráficos na imagem, é enfatizada pela passagem de um frame a outro, de modo que a diferença entre am- bos ressalta uma descontinuidade visual, a qual resulta inclusive na supressão de uma das palavras "asas". Teria ela voado para longe ou sumido nas fendas entre as descontínuas imagens?

Além disso, ainda nesse frame, o desenho de cada letra ganha um prolongamento vertical, ao contrário da primeira imagem, em que a superfície das asas era mais pronunciada à direita. Mais uma vez, com o movimento rápido do GIF animado, esses detalhes são quase imperceptíveis ao leitor, que tem apenas a impressão de que a imagem foi rotacionada e esticada verticalmente, causando distorção nas letras.

Por fim, no terceiro frame da série, notam-se dois conjuntos distintos de palavras "asas", cada um com seis ocorrências desse vocábulo. Tais conjuntos se superpõem parcialmente no centro da tela e criam o efeito icônico de um par de asas, entrelaçado nas curvas dos "s". O par de asas é estruturado a partir de dois eixos verticais de letras "a", rapidamente reconhecidos pelo leitor: um à esquerda, outro à direita do poema. No centro, as letras "s" de ambos os grupos de vocábulos "asas" geram um efeito de cascata, com intenso ritmo visual, e chegam a nos sugerir, devido ao cruzamento entre os "s", figurações do símbolo do infinito - infinitude, aliás, inerente ao funcionamento de qualquer GIF animado.

No movimento que esse poema digital enseja, destacam-se não apenas os elementos estéticos aqui analisados em sequência linear, mas sobretudo um efeito 
visual análogo ao do caleidoscópio - ou da droga de que fala Barthes (1970) -, que cria novos movimentos com os mesmos elementos gráficos, a cada troca de imagem. Nessa série poética, linhas curvas ora são apenas contornos plásticos de asas, ora desenham as letras com que se escreve "asas", oscilando entre o verbal e o não verbal a cada rotação do caleidoscópio digital. Nesse jogo de repetição e rotação, pode-se entrever ainda um efeito quase hipnótico, em que se vai das "asas", como palavra delineada, às asas de formas variadas, que se afastam, se encontram, se deformam; movimentam-se, enfim.

Este efeito de caleidoscópio remete-nos à ideia kristevariana de intertextualidade, segundo a qual "qualquer texto se constrói como um mosaico de citações e é absorção e transformação de outro texto" (2005, p. 64). Para além do diálogo entre textos que o conceito de intertextualidade enseja - explorado à exaustão pelos estudos literários comparatistas -, ressaltem-se aqui as metáforas de absorção e transformação. Afinal, o GIF animado "Asas" é fruto de um movimento intertextual não só na condição de transposição de um poema impresso. Mais do que isso, é intertextual porque engendra uma imagem que vai sendo absorvida e transformada ao longo de uma ininterrupta série, numa condição de devir outra (mas também devir a si mesma) na dialética entre diferença e repetição de que se constitui um GIF animado.
Ainda como caleidoscópio, um poema nesse formato é sempre diferente a cada novo olhar, revelando-se um significante em eterna movência, ou um par de asas a mudar eternamente de posição, como um móbile aos olhos do leitor.

Por sua vez, os jogos visuais que o poema em GIF "Volve" enseja têm um funcionamento significativamente distinto, ainda que também estruturado como um conjunto de imagens sequenciadas em um GIF animado. Tanto no suporte impresso quanto no digital, a série poética "Volve" é composta por nove imagens, as quais são reproduzidas a seguir, para fins de análise, a partir de capturas de tela do site de Arnaldo Antunes. Mais uma vez, sugere-se ao leitor que acesse o site do poeta, a fim de experienciar "Volve" nos diferentes recursos que o GIF animado enseja.

Figura 4 - Frames sucessivos do poema "Volve" em GIF animado
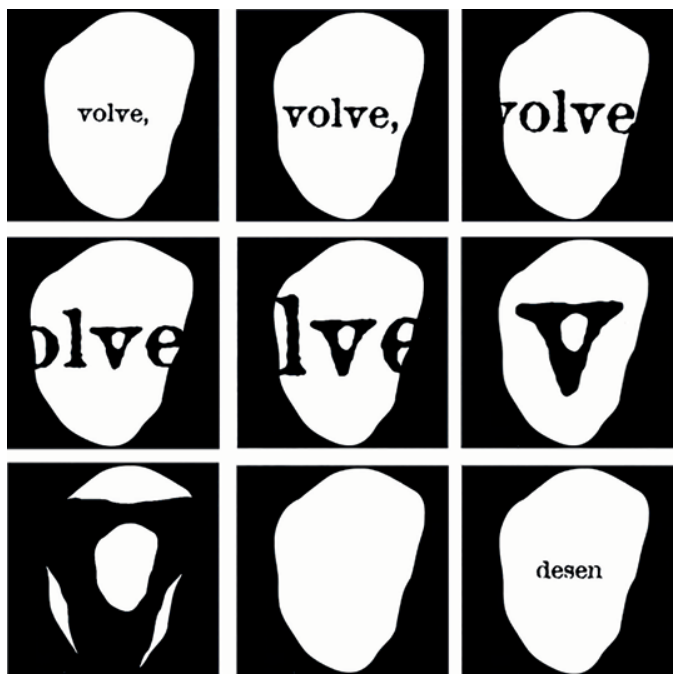

Fonte: Antunes ([201-?]). 
Uma mirada panorâmica da série logo mostra que, em "Volve", a tela do computador não faz as vezes de caleidoscópio. Em vez disso, a linguagem plástica aqui sugere que o instrumento óptico mediando o encontro do leitor com o poema é uma luneta, pois o movimento das imagens não simula uma rotação na tela, mas uma aproximação do foco visual.

$\mathrm{Na}$ primeira imagem, destacam-se elementos verbais formando a palavra "volve", grafada em fonte Attic Antique, seguida por uma vírgula. Tais elementos, em cor negra, estão circundados por uma superfície branca de contornos curvos e irregulares; esta, por sua vez, encontra-se cercada por um fundo preto. Os diversos encaixamentos que compõem essa imagem, bem como as demais que integram o poema, dão uma nova significação à palavra "volve": essa composição plástica se delineia na medida em que diversas formas envolvem os elementos verbais do poema, os quais sofrerão uma série de mudanças - porque se revolvem - ao longo das transformações do GIF animado.

Ainda nessa primeira imagem, é curiosa a presença da vírgula ao lado de "volve", dado que não há de fato aí uma frase cujas palavras precisem ser separadas por um sinal de pontuação. Considerando que vírgulas são usadas em variadas línguas para marcar relações e/ou fronteiras sintáticas entre termos de uma sentença, a presença desse sinal gráfico no primeiro frame de "Volve" sugere a existência de outros termos não aparentes, talvez ocultos sob a mancha negra na borda da imagem.
Caso o observador pudesse olhar mais de longe os elementos verbais do poema, talvez aparecessem, na área branca, elementos verbais potencialmente ocultos até então sob o fundo preto. Todavia, como dito anteriormente, o instrumento óptico que medeia a relação entre o leitor e a série "Volve" é uma luneta. Assim, não é possível se afastar dos elementos verbais do poema: uma luneta só faz as coisas parecerem mais próximas, e não mais distantes. Com o desenrolar do GIF, o leitor tem a impressão de ir progressivamente se aproximando das letras, como se nota na segunda e na terceira imagem da sequência poética. A superfície branca e o fundo preto, contudo, permanecem inalterados. Parecem, pois, fazer parte do próprio instrumento óptico (definindo o campo visual da luneta), e não dos objetos que se olha a distância (a palavra "volve" e a vírgula).

Desse modo, não sendo possível identificar outros elementos verbais com que "volve" formaria uma sentença, marcada graficamente pela vírgula, esse sinal de pontuação perde seu valor filológico para se tornar um operador de sintaxe visual. Nessa série poética, a vírgula não separa uma sequência escrita de substantivos ou verbos, como em uma enumeração, mas sim a sequência de imagens que estruturam o GIF animado. Só que essa enumeração não é encerrada nem por um ponto final, nem por reticências, como se faria num texto estritamente verbal escrito. Como o poema em GIF gira em loop, cada imagem tem uma 
vírgula, sucedida por uma outra imagem, contendo sua respectiva vírgula, e assim sucessivamente ad infinitum. O poema volve, pois, ao ponto inicial a cada nove frames, mas apenas para continuar indefinidamente suas transformações.

Acompanhando a sequência de imagens do $G I F$, do primeiro ao quinto frame, vai-se aproximando o leitor da palavra, que passa a não mais caber no campo visual da luneta. Suas letras vão sendo progressivamente engolidas pelo espaço branco, e o leitor, dada a velocidade das mudanças na imagem, sente-se tragado por uma fenda branca, na superfície preta, como se caísse em um abismo. Nesse processo, a palavra "volve" vai perdendo sua legibilidade, e a dimensão verbal do poema vai progressivamente desaparecendo, dando lugar a formas não icônicas, segundo "[...] a lógica única e exclusiva do ruído, ou seja, da não significação, da vertigem do ir-para-frente" (SANTOS, 2003, p. 117).

Na paulatina aproximação que a luneta engendra ao longo da série, vão crescendo as proporções das letras diante do leitor, que, na sexta imagem, vê apenas o que era a letra "v", mas agora revelando um gesto que, sem a luneta, não se enxergaria: as serifas superiores do " $\mathrm{v}$ " se unem em uma linha horizontal contínua. Assim, o que era até então interpretado apenas como letra, na vizinhança dos outros grafemas da palavra "volve", torna-se também uma forma negra algo semelhante a um triângulo invertido, com uma mancha branca no meio.
Essa passagem do verbal ao não verbal, presente também ao longo da série "Asas", forma uma imagem indecidível (DERRIDA, 1972) entre a letra e o rabisco. Tal processo faz vacilar as bases interpretativas do poema, que devolve, porque repele, todas as tentativas de atribuir um sentido único e estável àquilo que é puro movimento. Esse paradoxo entre o que há de igual e o que há de díspar entre o tracejado do "v" e o do triângulo remete-nos à proposição de Deleuze (1988, p. 75), para quem o jogo da repetição é dado como um transvasar do diferente a partir do mesmo: "Transvasar à repetição algo novo, transvasar-lhe a diferença (...)". Transvasado o grafema, por uma repetição que lhe esvazia a condição de letra, emerge dele apenas uma forma geométrica - ponto, linha, plano ou o que o valha -, tal como a concavidade do "v" que se torna mancha branca circunscrita a um triângulo na sexta imagem do GIF animado.

A passagem da sexta para a sétima imagem da série ressalta ainda outro dado que poderia passar despercebido pelo leitor, dado o curto intervalo de tempo que tem diante de cada frame: a mancha branca no centro do triângulo invertido é uma replicação (homotética) em tamanho menor da superfície branca em que a palavra "volve" estava escrita, o que reforça a sensação visual de abismo em que se lança o leitor na voragem do $G I F$. Por sua vez, a indecidível figura entre um "v" e um triângulo invertido toma quase todo o espaço da superfície branca original, indo ao encontro das bordas 
negras da imagem. Restam apenas três áreas brancas, nas laterais e acima do triângulo que vem ao encontro do leitor.

$\mathrm{Na}$ oitava imagem da série, a área branca no interior do triângulo invertido revela sua total simetria com a forma branca que circundava a palavra "volve" e a vírgula no primeiro frame. Aparentemente de volta ao início do poema, o leitor não sabe mais se está diante do começo ou do fim de um processo - vertigem esperada em um gênero poético que funciona por operações seriais em loop. A diferença única em relação ao primeiro frame do GIF animado é que agora o espaço branco é imaculado, como se, com o aproximar-se infinito da luneta, nada mais houvesse a ser visto, revelando a vacuidade no centro de todo signo. A palavra "volve" revela, desse modo, um vazio que é gráfico, na concavidade do "v", mas também semântico, uma vez que, por trás de todo significante, quando olhado bem de perto, com uma luneta, vê-se apenas uma lacuna, ou intervalo - que Derrida (1972) chamou de différance, e o GIF animado materializa no hiato entre distintos frames.

Já na nona imagem, o branco mallarmaico que a luneta revelara é maculado por cinco letras que, sozinhas, não formam um vocábulo em língua portuguesa: "desen". Nesse caso, se em "Asas" a desautomação da leitura se dava pela garatuja com que se traçavam as letras, em "Volve" é a segmentação de palavras - apresentando seus fragmentos, produto de cortes ou do zoom da luneta - que obstrui a leitura fácil, rejeitada por toda poesia.
Na versão impressa de "Volve", tem o leitor de associar mentalmente as sílabas de "desen" e "volve", para formar a palavra motriz do poema, que se constrói, afinal, como o desenvolvimento de uma série de imagens. Já no GIF animado, o efeito de repetição infinita permite que, quando o ciclo se reinicia e o nono frame dá lugar ao primeiro, o leitor veja se estabelecer diante dos seus olhos a sequência "desen" e "volve" - mas jamais simultaneamente na tela -, potencializando a ideia de movimento inerente a esse gênero poético e a transformação de elementos verbais em não verbais, $e$ vice-versa, ressaltando o tênue limiar entre tais instâncias.

\section{Considerações finais}

No âmbito da literatura digital, muito trabalho ainda precisa ser feito para mapear os gêneros emergentes, suas características expressionais e as formas como diferentes autores se apropriam deles para diferentes projetos poéticos. Nesse contexto, o presente artigo analisou o gênero GIF poem animado, realizando um exercício de leitura de duas séries poéticas que Arnaldo Antunes originalmente publicara em suporte impresso e depois transpôs para o universo digital: "Asas" e "Volve".

As discussões aqui apresentadas apontam para algumas características comuns a obras desse gênero, como a verbovisualidade e o efeito de vertigem do leitor diante das imagens que se alteram e reiteram em loop, segundo 
uma cadência constante. Nesse sentido, destaque-se que a experiência estética do GIF poem animado não é condicionada unicamente pelos tempos do leitor, da enunciação e do enunciado, uma vez que se torna de suma relevância aqui o tempo determinado pelo sistema. Como não há ainda nos estudos literários uma categoria analítica específica para a temporalidade dos sistemas digitais que integram a literatura eletrônica, faz-se necessário, pois, expandir formulações teóricas para conceptualização dessa dimensão estético-temporal.

No caso específico dos poemas "Asas" e "Volve", uma breve análise quantitativa pode destacar a influência do tempo do sistema no processo de leitura de poemas em GIFs animados. A série "Asas", com duração de 6,26 segundos, apresenta três imagens distintas; por sua vez, "Volve", com 21,72 segundos, apresenta nove imagens. Sabendo que as imagens se sucedem sempre em ritmo constante em um GIF animado, esses dados já mostram que as diferenças na quantidade de imagens e na duração de cada série implicam, necessariamente, uma distinção em termos de frequência: cada imagem de "Asas" é exibida ao leitor por 2,08 segundos antes de ser trocada pela próxima; no caso de "Volve", as imagens mudam a cada 2,41 segundos. Isso significa dizer que o ritmo de "Asas" é significativamente mais acelerado: ainda que 0,33 segundos pareça pouco tempo, o período de persistência da visão humana (tempo para distinguir duas imagens diferentes em uma sequência temporal) é de cerca de 0,06 segundos, o que torna significativo o contraste entre a frequência dos poemas em GIF animado "Asas" e "Volve".

Tais valores se tornam ainda mais relevantes se pensarmos que "Asas" opera por meio de uma semiótica da ilegibilidade muito mais pronunciada. Enquanto as letras de "Volve" são facilmente identificadas, dada a tipografia claramente reconhecível, "Asas" se constrói como um conjunto de garatujas sobrepostas, as quais acabam por formar o vocábulo "asas" e mesmo desenhar um par de asas, mas apenas discernível após algumas rotações do ciclo, dada a velocidade de transição das imagens e os emaranhados volteios das letras.

Além disso, tomaram-se como operadores de leitura desses textos duas metáforas de instrumentos ópticos: o caleidoscópio e a luneta. Tais aparelhos são utilizados, no universo extraliterário, para alterar o campo visual humano e o processo de reconhecimento de objetos, seja pelo estilhaçamento das imagens, no caso do caleidoscópio, seja pela aproximação do foco visual, no caso da luneta.

Esses diferentes efeitos ópticos revelam-se, no caso do GIF poem, balizas conceituais para compreender as distintas visualidades que as sequências de frames ensejam. A mudança de uma imagem para a outra, na sequência poética, pode, portanto, indicar uma rotação do foco, uma aproximação, um distanciamento, uma inversão, ou tantos outros fenômenos ópticos quanto os jogos de lentes possam estabelecer. 
Invariável, porém, é a condição de infinitude potencial que o GIF poem encerra, paradoxalmente exercitando, pela repetição em loop de um número finito de imagens, uma mirada do infinito óptico, em séries verbo-visuais que se desenrolam até que o olho esgote, canse ou perca-se em êxtase com a apreciação. Em tal dinâmica, revisitam-se o caráter reiterativo de toda poesia e a dimensão dinâmica de toda performance, frentes estéticas em que Antunes se destacou do impresso ao digital, da palavra à imagem, da voz ao corpo, da página ao GIF.

\section{A proposal of analysis of the genre GIF poem based on "Asas" and "Volve", by Arnaldo Antunes}

\begin{abstract}
Medium, by integrating and determining new aesthetical experiences, fosters different ways of interacting and reading poetic textualities. In the context of the new media from the digital revolution, the GIF format, popular in virtual environments, has been used in the re-elaboration of poems originally published in print media. In that context, this paper analyzes two transpositions of the poetic series "Asas" and "Volve", by Arnaldo Antunes, into the genre animated GIF poem. We herein analyze the verbivisual dynamics established by those poems and how they are enhanced by motility, speed and repetition, which are inherent to this new digital poetry genre. To do so, we discuss spatiotemporal issues of visual poetry within the transposition of "Asas"
\end{abstract}

and "Volve" into the GIF format, in the light of the metaphors of the kaleidoscope and the telescope, optical instruments that mediate the relation between the one who observes and the thing that is observed, thus poetically denaturalizing perception.

Keywords: Arnaldo Antunes. GIF poems. Motility. Repetition.

\section{Notas}

1 Disponível em: <http://www.arnaldoantunes. com.br>.

2 No website do artista, não constam títulos para tais textos. Para fins de clareza na identificação dos poemas em $G I F$, optamos aqui por adotar os mesmos títulos constantes nas versões impressas de tais textos.

3 Este poema, intitulado "Agouro", também foi publicado em versão impressa na obra $2 \mathrm{ou}+$ corpos no espaço (ANTUNES, 2012, p. 116).

4 Tais denominações inserem-se no campo das noções de fotopoéticas ou fotopoesia exploradas como implicações estéticas das duas artes: fotografia e poesia, como se pode notar nos trabalhos do poeta português Fernando Aguiar e nas produções do grupo de pesquisa Fotopoética, dirigido pelo Prof. Dr. Carlos Alberto Murad, no Programa de Pós-Graduação em Artes Visuais (EBA), da Universidade Federal do Rio de Janeiro.

5 Nós relemos imediatamente o texto, é para obter, como sob o efeito de uma droga (aquela do recomeço, da diferença), não o "verdadeiro" texto, mas o texto plural: o mesmo e o novo (Tradução nossa).

6 Os ordinais "primeira", "segunda", "terceira”, etc. são utilizados ao longo deste artigo apenas para fins de clareza na análise, devendo ser tomados apenas como indicativos de uma posição relativa. Isso porque, num GIF animado de três imagens, por exemplo, como a sequência de frames se repete indefinidamente, a primeira imagem logo vira a quarta, depois a sétima e, assim, sucessivamente. Além disso, se um leitor pisca os olhos quando inicia um GIF animado, pode "perder" a primeira imagem e achar que aquela sequência se inicia pelo segundo frame (ou qualquer outro). 


\section{Referências}

ANTUNES, Arnaldo. Arnaldo Antunes ao vivo em Lisboa. ([201-?]). Disponível em: <http:// www.arnaldoantunes.com.br>. Acesso em: 12 abr. 2017.

2 ou + corpos no mesmo espaço. 3. ed. São Paulo: Perspectiva, 2012.

Tudos. São Paulo: Iluminuras, 2015.

AMARAL, Ludmila Lupinacci. As apropriações do GIF animado: aspectos culturais, expressivos e afetivos dos usos de uma tecnologia defasada. 2016. 279 f. Dissertação (Mestrado em Comunicação e Informação) - Programa de Pós-Graduação em Comunicação e Informação da Faculdade de Biblioteconomia e Comunicação, Universidade Federal do Rio Grande do Sul, Porto Alegre, 2016.

ALCÂNTARA, Simone Silveira. Arnaldo Antunes, trovador multimídia. 2010. Tese (Doutorado em Literatura Brasileira) - Programa de Pós-Graduação em Literatura Brasileira do Departamento de Teoria Literária e Literaturas (TEL), Universidade de Brasília, Brasília, 2010.

BARTHES, Roland. Combien de lectures? In:__. S / Z . Paris: Seuil, 1970. p.22-23.

DELEUZE, Gilles. Diferença e repetição. Trad. Luiz Orlandi e Roberto Machado. Rio de Janeiro: Graal, 1988.

DERRIDA, Jacques. Margens da Filosofia. Lisboa: Rés, 1972.

ELO - ELECTRONIC LITERATURE ORGANIZATION. What's E-lit? 2015. Disponível em: $<$ http://eliterature.org/what-is-e-lit/>. Acesso em: 20 jul. 2017.

FERREIRA, Ana Paula. Espaço e poesia na comunicação em meio digital. 2010. Tese (Doutorado em Ciências Sociais Aplicadas: Comunicação) - Programa de Pós-Graduação em Comunicação e Semiótica, Pontifícia Universidade de São Paulo, São Paulo, 2010.
GENETTE, Gérard. Palimpsesto: a literatura de segunda mão. Trad. Luciene Guimarães e Maria Antônia Ramos Coutinho. Belo Horizonte: FALE/UFMG, 2006.

GREIMAS, Algirdas Julius. Semântica Estrutural. São Paulo: Cultrix, 1973.

HAYLES, Katherine. The Time of Digital Poetry: from object to event. In: MORRIS, Adalaide; SWISS, Thomas. New Media Poetics: contexts, technotexts and theories. Cambridge: MIT, 2006. p. 181-210.

KRISTEVA, Julia. Introdução à Semanálise. Trad. Lúcia Helena França Ferraz. 2. ed. São Paulo: Perspectiva, 2005.

KOSKIMAA, Raine. Approaches to Digital Literature: temporal dynamics and cyborg authors. In: SIMANOWSKI, Roberto; SCHÄFER, Jörgen; GENDOLLA, Peter. Reading Moving Letters: digital literature in research and teaching. Bielefeld: Transcript, 2010. p. 129-144.

MORAES, Joeci Helena. Arnaldo Antunes e obra 2 ou + corpos no mesmo espaço: uma prática de escritura plural. 2007. Dissertação (Mestrado em Letras) - Programa de Pós-graduação em Letras, Universidade de Santa Cruz do Sul, Santa Cruz do Sul, 2007.

MCLUHAN, Marshall. Os meios de comunicação como extensões do homem. São Paulo: Cultrix, 1974.

NADAL, João Henrique Duarte. A cultura do $G I F$ : reconfigurações de imagens técnicas a partir dos usos e apropriações de narrativas cíclicas. 2014. 185 f. Dissertação (Mestrado em Ciências Sociais Aplicadas: Comunicação) Programa de Pós-Graduação em Comunicação e Linguagens, Universidade Tuiuti do Paraná, Curitiba, 2014.

SANTOS, Alkmar Luiz dos. Leitura de nós: ciberespaço e literatura. São Paulo: Itau Cultura, 2003. 